\title{
Selective formation of light olefins from dimethyl ether over MCM-68 modified with phosphate species
}

\author{
Sungsik Park ${ }^{\mathrm{a}}$, Satoshi Inagaki ${ }^{\mathrm{a}}$ and Yoshihiro Kubota ${ }^{\mathrm{a}, \mathrm{b}}$ \\ ${ }^{a}$ Division of Materials Science and Chemical Engineering, Yokohama National University, 79-5 \\ Tokiwadai, Hodogaya-ku,Yokohama 240-8501, Japan. \\ ${ }^{\mathrm{b}}$ CREST, Japan Science and Technology Agency, 4-1-8 Honcho, Kawaguchi, Saitama 332-0012, \\ Japan.
}

E-mail: kubota@ynu.ac.jp; Fax:+81-45-339-3941; Tel: +81-45-339-3926

\begin{abstract}
To control the acid sites distribution in MCM-68 zeolite catalyst, phosphate-loaded MCM-68 catalyst was prepared by impregnation with aqueous solution of $\left(\mathrm{NH}_{4}\right)_{2} \mathrm{HPO}_{4}$ onto MCM-68 and subsequent calcination. Phosphate impregnation was effective for increasing the selectivity to propylene and butylenes. The propylene/ethylene ratio in the products was significantly increased by phosphate modification. The considerable enhancement of the yields of propylene and butylenes could be attributed to reduction of stronger acid sites, especially the acid sites distributed on the external surface of MCM-68 catalyst. Furthermore, phosphate-modified MCM-68 showed high durability to coke formation, indicating this modification technique is useful to obtain long-lived catalysts in DTO reaction.
\end{abstract}

\section{Introduction}

Catalytic conversion of methanol or dimethyl ether into light olefins, especially propylene, has attracted huge attention because the world-wide demands of propylene as well as ethylene are steadily increasing both now and in the near future [1]. As thermal cracking of ethane, supplied from fossil oil, natural gas or shale gas, gives a high selectivity to ethylene (more than $80 \mathrm{wt} \%$ ) under the thermodynamic limitation [2], it satisfies ethylene demand but not propylene [3]. Therefore, the alternative processes for the production of propylene are instantly required. Propylene, which can be converted into the important and useful chemicals such as propylene oxide, acrolein, acrylic acid and related polymers, has been mainly produced through thermal cracking or fluid catalytic cracking 
(FCC) of naphtha [4]. Recently, on-purpose technologies, such as methanol-to-olefin (MTO), and dimethyl ether-to-olefin (DTO) reactions [5-8] as well as olefin interconversion [9], metathesis of ethylene and butylene [10] and dehydrogenation of propane [11] have been developed for the production of propylene. Among them, the DTO and MTO processes, which can apply natural gas and other non-petroleum feedstocks instead of fossil oils as a resource, are the most feasible because they have huge possibility to improve a propylene yield by tuning of the catalysts $[12,13]$.

During the past decades, a variety of solid acid catalysts have been explored as possible DTO and MTO catalysts and it is acknowledged that the performance of catalysts depends strongly on both the framework structure and their acidic characteristics [13-18]. ZSM-5 zeolite is the first commercial catalyst used for methanol-to-gasoline (MTG) process and the most widely studied catalysts for the DTO and MTO reaction due to its high thermal stability and higher resistance to coke deposition [15]. The control of product selectivity has been the main issue for the MTO process. Various methods such as incorporation of metallic ( $\mathrm{Zr}$ [19], Ce [20], or $\mathrm{Ca}[21,22])$ and/or non-metallic promoters (B [22] or P [22-30]) into ZSM-5 have been suggested to improve the selectivity to light olefins on ZSM-5 catalysts. Phosphate modification is known as a feasible method to adjust the acidity of zeolite catalysts [23-30]. Particularly, modification of zeolite catalysts by phosphate impregnation has been proven to be effective to change the product selectivity in MTG reaction over ZSM-5 [23-30]. Jang et al. suggested that the modification of ZSM-5 with phosphate species neutralized its strong acid sites, resulting in a high selectivity to light olefins by limiting the further reactions from the light olefins to saturated aliphatic and aromatics [28], while Vedrin et al. suggested that the changes in selectivity were mainly assigned to the narrowing of pore size due to phosphate compounds bonding to the zeolite framework, rather than to changes in acid strength [30].

MCM-68 is a new type of three-dimensional zeolite framework with a $12 \times 10 \times 10$-ring channel system [35]. This framework (MSE as the framework type code) [36] has a characteristic structure in which a straight 12-ring channel intersects with two inter-connected, tortuous 10-ring channels and possesses an 18-ring $\times 12$-ring supercage which is accessible only through 10-ring channels [36]. MCM-68 is known to prominent candidates for designing novel catalysts due to their availability in a wide range of Si/Al ratios [37]. Such MCM-68 zeolites exhibit unique acid catalytic properties and are potentially useful as shape-selective catalysts for the alkylation of aromatics [39-41], as well as 
for the production of propylene in hexane-cracking $[38,42]$. Their use as hydrocarbon traps has also been reported [43]. In addition, the post-synthetic isomorphous substitution of Ti for Al in the MSE framework extends their application as the catalyst for the oxidation of phenol and olefins with $\mathrm{H}_{2} \mathrm{O}_{2}$ as an oxidant $[37,43]$.

As mentioned above, dealumination, one of the post-synthetic techniques, is practicable to vary the content of $\mathrm{Al}$ present in the framework of MCM-68. Due to the reduced density of acid sites, such MCM-68 exhibited significantly enhanced selectivity to propylene with high propylene-to-ethylene $(\mathrm{P} / \mathrm{E})$ ratio in DTO reaction $[37,45]$. In this work, a phosphate-modified MCM-68 was prepared by $\left(\mathrm{NH}_{4}\right)_{2} \mathrm{HPO}_{4}$ impregnation. We focused on the changes in the acidity of MCM-68 and the corresponding changes in catalytic selectivity of the products in the reaction of dimethyl ether conversion after phosphate modification.

\section{Experimental}

\subsection{Catalyst preparation}

For the synthesis of MCM-68 with Si/Al molar ratio of 10, colloidal silica (Ludox HS-40, DuPont, $40 \mathrm{wt} \% \mathrm{SiO}_{2}$ ), de-ionized water and $\mathrm{Al}(\mathrm{OH})_{3}$ (Pfaltz \& Bauer) were mixed for $10 \mathrm{~min}$. Aqueous $\mathrm{KOH}$ solution $\left(5.93 \mathrm{mmol} \mathrm{g}^{-1}\right)$ was added to the solution, and stirred for further $30 \mathrm{~min}$. Then, $N, N, N^{\prime}, N^{\prime}$-tetraethylbicyclo[2.2.2] oct-7-ene-2,3:5,6-dipyrrolidinium diiodide $\left(\mathrm{TEBOP}^{2+}\left(\mathrm{I}^{-}\right)_{2}\right)$ was added as a structure-directing agent (SDA), and the mixture was stirred for another $4 \mathrm{~h}$. The resulting mixture with a molar composition $1.0 \mathrm{SiO}_{2}-0.1 \mathrm{TEBOP}{ }^{2+}\left(\mathrm{I}^{-}\right)_{2}-0.375 \mathrm{KOH}-0.1 \mathrm{Al}(\mathrm{OH})_{3}-30 \mathrm{H}_{2} \mathrm{O}$ was taken into a Teflon-lined autoclave, and kept statically at $160{ }^{\circ} \mathrm{C}$ for $16 \mathrm{~d}$ in a convection oven. After quenching the autoclave in an ice bath for $30 \mathrm{~min}$, the solid part was separated by centrifugation, washed several times with de-ionized water until the $\mathrm{pH}$ value of the decanted water reached around 7, and dried overnight at $100{ }^{\circ} \mathrm{C}$. The as-synthesized MCM-68 zeolite was calcined at $650{ }^{\circ} \mathrm{C}$ for 10 $\mathrm{h}$ to eliminate SDA. After the calcination, the potassium form of MCM-68 was converted into the $\mathrm{NH}_{4}{ }^{+}$form by exchanges in $0.5 \mathrm{~mol} \mathrm{~L}^{-1}$ aqueous solution of $\mathrm{NH}_{4} \mathrm{NO}_{3}$ at $80{ }^{\circ} \mathrm{C}$ for $12 \mathrm{~h}$, followed by filtration and washing. This procedure was repeated four times and $\mathrm{NH}_{4}{ }^{+}$form of MCM-68 was dried at $100{ }^{\circ} \mathrm{C}$ for $12 \mathrm{~h}$ and calcined at $550{ }^{\circ} \mathrm{C}$ for $4 \mathrm{~h}$ to obtain the proton form of MCM- 68 .

MCM-68 zeolite with Si/Al molar ratios of 60 was prepared by treating of potassium form of 
MCM-68(10) with aqueous $\mathrm{HNO}_{3}$ solution $\left(2 \mathrm{~mol} \mathrm{~L}^{-1}, 100 \mathrm{ml}\right.$ of solution for $1 \mathrm{~g}$ of zeolite) at $80{ }^{\circ} \mathrm{C}$ for $2 \mathrm{~h}$. After cooling to room temperature, the solid part was separated by centrifugation, washed several times with de-ionized water, and dried overnight at $100{ }^{\circ} \mathrm{C}$.

The phosphorus loaded MCM-68 zeolites were prepared from proton forms of MCM-68 with $\mathrm{Si} / \mathrm{Al}$ molar ratios of 10 and 60 . For the phosphorus impregnation, $0.5 \mathrm{~g}$ of zeolites were impregnated in aqueous solution of $\left(\mathrm{NH}_{4}\right)_{2} \mathrm{HPO}_{4}\left(0.21 \mathrm{~mol} \mathrm{~L}^{-1}, 1.0 \mathrm{~mL}\right)$ at room temperature for $30 \mathrm{~min}$. Then, phosphate-modified MCM-68 was dried at $100{ }^{\circ} \mathrm{C}$ for $12 \mathrm{~h}$ and calcined at $550{ }^{\circ} \mathrm{C}$ for $4 \mathrm{~h}$ to obtain the proton form of MCM-68. In this paper, the phosphate-modified MCM-68(60) is designated as $\mathrm{P} / \mathrm{MCM}-68(60)$. The number in parentheses is the $\mathrm{Si} / \mathrm{Al}$ molar ratio.

\subsection{Characterization}

Crystal structures of the obtained solid products were determined by X-ray powder diffraction (XRD) on an Ultima IV (Rigaku) using CuKa radiation at $40 \mathrm{kV}$ and $20 \mathrm{~mA}$. The textural properties of the catalysts were examined by $\mathrm{N}_{2}$ adsorption-desorption isotherm measurement at $-196^{\circ} \mathrm{C}$ with an Autosorb-iQ analyzer (Quantachrome Instruments). Before the measurements, all the samples were evacuated at $400{ }^{\circ} \mathrm{C}$ for $4 \mathrm{~h}$. Micropore volumes of the catalysts were calculated from the adsorption isotherm by the $t$-plot method. Specific surface areas of the catalysts were calculated from the adsorption isotherm by the Brunauer-Emmett-Teller (BET) equation. For a surface area evaluation, data in the relative pressure range of $0.05-0.10$ are used. The chemical compositions of zeolites were determined by using inductively coupled plasma atomic emission spectrometer (ICP-AES, ICPE-9000, Shimadzu). The shape and the particle size of the MCM-68 zeolites were observed by a scanning electron microscope (JSM-7001F, JEOL).

The properties of acid sites on catalysts were measured by ammonia temperature-programmed desorption ( $\mathrm{NH}_{3}$-TPD) measurement on a BELCAT-B (Japan Bel Inc.) equipped with a thermal conductivity detector (TCD). Before the measurements, the catalysts $(50 \mathrm{mg})$ charged in a quartz-tube were preheated at $600{ }^{\circ} \mathrm{C}$ prior to the measurement under He flow. The TPD data were collected at a ramping rate of $10{ }^{\circ} \mathrm{C} \mathrm{min}^{-1}$. The number of acid sites was determined from the area of $h$-peak [46] in their profiles. For Fourier transform infrared (FT-IR) spectroscopy analysis, self-supporting zeolite wafer (20-30 mg) was located between $\mathrm{NaCl}$ windows in a cylindrical cell 
similar to that described in ref [47]. The sample was then heated to $550{ }^{\circ} \mathrm{C}$ at $5{ }^{\circ} \mathrm{C} \min ^{-1}$ under vacuum, held for $1 \mathrm{~h}$, and cooled to $100{ }^{\circ} \mathrm{C}$ prior to the adsorption experiments. Pyridine (ca. 2.7 $\mathrm{kPa}$ ) was injected into the cell. The cell was left in vacuum for $10 \mathrm{~min}$ to allow physically adsorbed pyridine to desorb. Spectra were then recorded and averaged over 32 scans between 450 and 4000 $\mathrm{cm}^{-1}$ with $4 \mathrm{~cm}^{-1}$ resolution. The temperature of the IR cell was progressively increased from 100 to $400{ }^{\circ} \mathrm{C}$ and the spectrum was recorded at $100,150,200,250,300,350$ and $400{ }^{\circ} \mathrm{C}$. The spectrum was recorded at least two times for each temperature (5-minute interval). The coke contents of the used catalysts were determined in a thermogravimetirc analyzer (TG-8120, Rigaku). The temperature was raised from room temperature to $800{ }^{\circ} \mathrm{C}$ with the rate of $10{ }^{\circ} \mathrm{C} \mathrm{min}-1$ under air flow $\left(30 \mathrm{~cm}^{3}\right.$ (N.T.P.) $\left.\min ^{-1}\right)$.

\subsection{Catalytic reactions}

Dimethyl ether (partial pressure: $5.0 \mathrm{kPa}$ ) was introduced into the top of the reactor (a down-flow quartz-tube microreactor with a 9-mm inner-diameter) with $\mathrm{He}\left(40 \mathrm{~cm}^{3}\right.$ (N.T.P) $\left.\mathrm{min}^{-1}\right)$. Each zeolite catalyst was pelletized without any binder, roughly crushed and then sieved to obtain catalyst pellets with 500-600 $\mu \mathrm{m}$ in size. Prior to running the reaction, $100 \mathrm{mg}$ of catalyst pellets were placed in the fixed bed of the reactor. The temperature of electric furnace was raised to the pretreatment temperature with the rate of $10{ }^{\circ} \mathrm{C} \mathrm{min}^{-1}$ under air flow $\left(40 \mathrm{~cm}^{3}\right.$ (N.T.P.) $\left.\mathrm{min}^{-1}\right)$. After pretreatment at $550{ }^{\circ} \mathrm{C}$ for $1 \mathrm{~h}$, the temperature was adjusted to reaction temperature under He flow $\left(40 \mathrm{~cm}^{3}\right.$ (N.T.P.) $\min ^{-1}$ ). The reactants and products were analyzed on DB-5 capillary column (i.d. $0.53 \mathrm{~mm}$; length 60 $\mathrm{m}$; thickness of the stationary phase $5.00 \mu \mathrm{m}$; Agilent Technology) and an HP-PLOT/Q capillary column (i.d. $0.53 \mathrm{~mm}$; length $30 \mathrm{~m}$; thickness of the stationary phase $40.0 \mu \mathrm{m}$; Agilent Technology) using a GC-2014 (Shimadzu) with a flame ionization detector (FID). The conversion of dimethyl ether, the selectivity of the products, the yield of the products and material balance were calculated on the carbon-basis of the inlet amount of dimethyl ether.

The cracking of cumene or 1,3,5-triisopropylbenzene (TIPB) was performed at $300{ }^{\circ} \mathrm{C}$ under atmospheric pressure in a pulse-type quartz-tube (i.d. $4 \mathrm{~mm}$ ) microreactor (see Fig. S1) under a stream of helium $\left(30 \mathrm{~cm}^{3}\right.$ (N.T.P.) $\left.\mathrm{min}^{-1}\right)$. The catalyst amount, dose amounts of cumene and TIPB are $20 \mathrm{mg}, 0.8 \mu \mathrm{L}$, and $0.6 \mu \mathrm{L}$, respectively. The products were analyzed by TCD on GC equipped 
with stainless steel column (i.d. $3.0 \mathrm{~mm}$; length $6.0 \mathrm{~m}$ ) packed with Silicone OV-1 (60-80 mesh).

\section{Results and discussion}

\subsection{Effect of phosphorus on the structure and acidity of MCM-68}

The XRD patterns of dealuminated MCM-68(60) showed that each sample maintained the MSE structure during dealumination and phosphate impregnation treatments (Fig. 1). As shown in SEM images in Fig. 2, the particle size of ion-exchanged MCM-68 zeolites was about $100 \mathrm{~nm}$. The SEM images of dealuminated (Fig.1.b) and further phosphate-modified MCM-68 (Fig.1.c) indicates that the particle size and the morphology shape did not change with acid treatment and further phosphate treatment. The specific surface area, micropore volume are listed in Table 1. The shapes of $\mathrm{N}_{2}$ adsorption-desorption isotherms of MCM-68(60) and P/MCM-68(60) were very similar (typical type-I isotherms), indicating that phosphate impregnation did not significantly change the micropore feature of MCM-68 (see Fig. S3). On the other hand, phosphate impregnation reduced the both micropore volume and specific surface area. Temperature programmed desorption slightly (TPD) profiles of $\mathrm{NH}_{3}$ of MCM-68 indicate two peaks at around $150-200{ }^{\circ} \mathrm{C}$ and $350-450{ }^{\circ} \mathrm{C}$ (Fig. 3). The area of the $h$-peak corresponding to the amount of acid sites did not change significantly during phosphate impregnation (Table 1).

The decrease in the micropore volume and the specific surface area after phosphate impregnation is probably due to the partial pore mouth blockage. Although $\mathrm{NH}_{3}-\mathrm{TPD}$ profiles cannot distinguish between Brønsted and Lewis acidity, the decrease in the area of $h$-peak after phosphate impregnation indicate that phosphate compounds are incorporated into MCM-68 by interacting with the acid sites.

\subsection{FT-IR of pyridine adsorbed on MCM-68 zeolites}

The FT-IR spectra of the MCM-68 zeolites activated at $500{ }^{\circ} \mathrm{C}$ for $1 \mathrm{~h}$ under vacuum and cooled down at $100{ }^{\circ} \mathrm{C}$ are shown in Fig. S4. The ranges of $3500-4000 \mathrm{~cm}^{-1}$ in the FT-IR spectra were focused on for detecting surface hydroxyl groups. FT-IR peaks at ca. 3789, 3747, 3734, 3667 and 3626 were observed for the MCM-68(10) in agreement with the findings of B. Gil et al [48]. As can be observed in Fig. S4, the differences between the FT-IR spectra of MCM-68(10) and MCM-68(60) were obviously seen, while the FT-IR spectra of MCM-68(60) and P/MCM-68(60) in the region of 
$3500-4000 \mathrm{~cm}^{-1}$ did not change. The peak at $3747 \mathrm{~cm}^{-1}$ is attributed to the $\mathrm{O}-\mathrm{H}$ vibrations in the $\mathrm{Si}(\mathrm{OH})$ groups on the external surface and that of at $3734 \mathrm{~cm}^{-1}$ is attributed to those in the $\mathrm{Si}(\mathrm{OH})$ inside a site defect [48]. The removal of $\mathrm{Al}$ atoms in the framework of MCM-68(10) by dealumination distinctly reduced the intensity of the peak which is due to $\mathrm{O}-\mathrm{H}$ vibrations in $\mathrm{Si}(\mathrm{OH}) \mathrm{Al}\left(3626 \mathrm{~cm}^{-1}\right)$, while the intensity of the peak which is due to $\mathrm{O}-\mathrm{H}$ vibrations in $\mathrm{Si}(\mathrm{OH})$ $\left(3728 \mathrm{~cm}^{-1}\right)$ increased.

Figure 4 shows FT-IR spectra in the region of $1400-1600 \mathrm{~cm}^{-1}$ after adsorption of pyridine on MCM-68(60) and P/MCM-68(60). FT-IR peaks at 1543 and $1454 \mathrm{~cm}^{-1}$, which are attributed to pyridinium ions (pyridine chemisorbed on Brønsted acid sites) and pyridine interacting with Lewis acid sites, were observed. These results indicate that both Brønsted and Lewis acid sites exist on MCM-68(60) and P/MCM-68(60). With the increase in temperature, the intensity of the peaks at 1543 and $1454 \mathrm{~cm}^{-1}$ decreased. In the case of P/MCM-68(60), the intensity of the peak at $1454 \mathrm{~cm}^{-1}$ significantly decreased with the increase in temperature and disappeared at the temperature of $400{ }^{\circ} \mathrm{C}$, while the corresponding peaks were still detected over MCM-68(60). Although the observation of temperature dependence of pyridine adsorbed on the Brønsted and Lewis acid sites could give us the information related to the relative strength of Brønsted and Lewis acid sites, the quantitative determination of the number of Brønsted and Lewis acid sites on MCM-68 seems inapplicable because the molar extinction coefficients over MCM-68 have not been investigated, to our best knowledge. Despite we have not been quantifying the number of strong or weak Brønsted and Lewis acid sites on MCM-68, the results of IR experiments indicate that the strength of Lewis acid sites on P/MCM-68(60) can be expected to be much weaker than that on the MCM-68(60) since the peaks at $1454 \mathrm{~cm}^{-1}$ due to the pyridine interacted with Lewis acid sites almost disappeared or decreased readily with increasing temperatures. These results indicate that the phosphate-modification on MCM-68 decreased the number of strong Lewis acid sites by covering them.

\subsection{Catalytic cracking of 1,3,5-triisopropylbenzene and cumene on MCM-68 zeolites}

Figure 5 shows the results of the catalytic cracking of 1,3,5-triisopropylbenzene (TIPB) and cumene on parent and P/MCM-68(60) at $300{ }^{\circ} \mathrm{C}$. Catalytic cracking of TIPB occurs only at acid sites on the external surface of MCM-68 because TIPB molecules are much larger than the pore diameters 
of the $12 \mathrm{R}$ and $10 \mathrm{R}$ micropores within the MSE framework. In contrast, cumene molecules, which are much smaller than TIPB molecules, can penetrate the 10R micropores in the MSE framework. Catalytic cracking of cumene thus evaluates the acid sites on both the external and internal surfaces of MCM-68 catalysts [38]. The initial TIPB conversion over MCM-68(60) was higher than that of P/MCM-68(60) and its catalytic activity maintained above $40 \%$ after 8 pulses of TIPB. In the case of P/MCM-68(60), the catalytic activity for the conversion of TIPB was very low from the first reaction pulse and then dropped rapidly to less than $1 \%$ at the third pulses of TIPB. In contrast, in terms of the cumene conversion, the initial activity of both parent and phosphate-modified MCM-68(60) was high (approximately $93 \%$ ) and the catalytic activity for cumene conversion over MCM-68(60) and P/MCM-68(60) was maintained almost constant.

The higher catalytic activity of parent MCM-68(60) in the TIPB conversion could be attributed to the large amount of acid sites on the external surface. The low catalytic activity of phosphate-modified MCM-68(60) in the TIPB conversion reaction indicates that the number of acid sites on the external surface of P/MCM-68(60) is lower than that of MCM-68(60). Despite the low catalytic activity of P/MCM-68(60) in TIPB cracking reaction, it showed approximately similar catalytic activity in cumene cracking reaction to that of parent MCM-68(60). These results indicate selective covering of external acid sites in MCM-68(60) during phosphate modification.

\subsection{Catalytic performance of MCM-68 in DTO reactions}

In our previous study, we investigated the effect of Si/Al molar ratio of MCM-68 on the catalytic performance for DTO reaction. The large number of acid sites on parent MCM-68(10) produced more $\mathrm{C}_{2}, \mathrm{C}_{3}$ and $\mathrm{C}_{4}$ paraffins, aromatics and hydrocarbons that have carbon numbers greater than 6 . On the other hand, the optimization of the number of acid sites by acid treatment gives MCM-68 with sufficient acid sites for the propylene production in DTO reactions [37,45]. This is because the undesirable consecutive reactions from the light olefins were suppressed by the optimization of the number of the acid sites on MCM-68.

In this work, we have compared the catalytic performance of dealuminated MCM-68(60) with phosphate-modified MCM-68(60). Comparison of the activity and selectivity over MCM-68(60) and P/MCM-68(60) in DTO reactions are presented in Figure 6 ( $a$ and b, respectively). When the 
contact-time, W/F, $\left(\mathrm{g} \mathrm{h} \mathrm{mol}^{-1}\right)$ was 20 , complete conversion of dimethyl ether to hydrocarbons over MCM-68 and P/MCM-68(60) occurred. In order to compare the product selectivity, the conversion level was tuned at around $95 \%$ by decreasing the catalyst loading from $100 \mathrm{mg}$ to $50 \mathrm{mg}$ (see Table 2). The product selectivity and DME conversion in DTO reactions over MCM-68(60) and P/MCM-68(60) are also shown in Figure 6d and 6e, respectively). Phosphate modification on MCM-68(60) slightly reduced the conversion since the more unreacted methanol and dimethyl ether were observed in the DTO reaction over P/MCM-68(60) in comparison with that over MCM-68(60). The selectivity to light olefins, except ethylene, greatly increased by phosphate modification, whereas the selectivity of aromatics (benzene, toluene, xylenes, 1,2,4-trimethylbenzene, 1,2,3-trimethylbenzene, 1,2,3,5-tetramethylbenzene, 1,2,4,5-tetramethylbenzene, pentamethylbenzene and hexamethylbenezene) and light paraffins (ethane, propane, butane and isobutane) decreased by phosphorus modification.

The product distributions were definitely different between the cases of MCM-68(60) and P/MCM-68(60), when using $100 \mathrm{mg}$ of catalysts (See Fig. 6). When catalyzed by MCM-68(60), the increase in catalyst loading from 50 to $100 \mathrm{mg}$ significantly increased the yield of ethylene and aromatics, particularly for pentamethylbenzene and hexamethylbenzene (Fig. 6a and 6d). In the case of P/MCM-68(60), the increase in catalyst loading increase the yield of propylene from ca. 40 to ca. $50 \mathrm{C}$-atom \%, while that of aromatics and ethylene did not drastically change (Fig. 6b and 6e). In order to clarify the effect of treatment with phosphate on acidity of MCM-68, MCM-68 with the $\mathrm{Si} / \mathrm{Al}$ molar ratio of 84 , which possesses the lesser amount of acid sites than MCM-68(60), was applied in DTO reaction at the same reaction conditions (shown in Fig. 6c and 6f). When catalyzed by MCM-68(84), the increase in the yield of propylene and butylenes and the subsequent decrease in the yield of aromatics and paraffins were observed. This is in good agreement with our previous research reporting a catalytic performance of MCM-68 with various Si/Al molar ratios [37,45]. On the other hand, there is slight difference in product distributions, that is, the reaction over phosphate-modified P/MCM-68(60) resulted in higher yields of propylene and butylene compared to that over unmodified MCM-68. Furthermore, the propylene/ethylene (P/E) ratio in products significantly increased with phosphate modification (from 16 to 42). These results indicate that a certain active sites, which may be responsible for the formation of aromatics (especially 
pentamethylbenezene and hexamethylbenzene) and ethylene, decreased by phosphate impregnation on MCM-68(60). One of the most undesirable side reactions in the DTO reaction is olefin aromatization. The P/MCM-68(60) showed decreased aromatic selectivity compared with MCM-68(60) and MCM-68(84), probably due to a decrease in the number of strong Lewis acid sites, which is known to catalyze aromatization and hydrogen transfer reactions.

The spent catalysts were characterized by TG/DTA to determine their coke contents. A distinct weight loss, accompanied by an exothermic DTA peak, was observed at the temperature range of around $300-700{ }^{\circ} \mathrm{C}$. This is mainly related to combustion of the carbonaceous material deposited on the catalysts during DTO reactions. According to the results from TG/DTA, the amount of coke deposited on P/MCM-68(60) was lower than that of MCM-68(60) (Table 2 and Fig. S5). These results indicate that phosphate impregnation on MCM-68 catalyst could improve the tolerance for coke deposition during DTO reaction. Coke, which should be considered as a mixture of hydrogen deficient residues, originates mainly from aromatics [49], thus aromatization and hydrogen transfer reactions are highly important contributors to coke deposition. The enhanced durability to coke deposition during DTO reaction over P/MCM-68(60) is probably due to the decrease in the number of stronger Lewis acid sites, which take part in the formation of aromatics from the conversion of dimethyl ether, by phosphate impregnation (Fig. 4).

Conversely, the low ethylene selectivity observed over P/MCM-68(60) is probably due to the changes in the number of strong Brønsted acid sites because the formation of ethylene is proceed through carbenium cation resulted by the cracking reactions of intermediates [50]. F. Bleken et al. reported catalytic results of MTO reaction over SSZ-13 and SAPO-34 catalysts [51]. The high P/E ratios in products were obtained when catalyzed by SSZ-13, which has the same topology and the number of acid sites, but is slightly more acidic due to the framework composition. They concluded that the differences in acid strength may affect the product distribution in MTO reactions. By considering the energy level of the primary carbenium ions, which is higher than that of the secondary and tertiary carbenium ion [52], the formation of ethylene, which has to go through primary carbenium ions, proceed readily with the existence of the stronger acid sites on catalysts. Although we could not obtain a reliable result showing the decrease in the number of strong Brønsted acid sites on MCM-68 by phosphate-modification, we believe that the high P/E ratio in 
products obtained P/MCM-68 is probably due to the decrease in the number of strong Brønsted acid sites.

\section{Conclusions}

MCM-68(60) and phosphate-loaded MCM-68(60) zeolites were synthesized by the post-treatment of hydrothermally synthesized MCM-68(10). The results obtained from the DTO reactions indicate that the P/MCM-68(60) is an effective catalyst for the selective production of light olefins such as propylene and butylene. The impregnation of MCM-68 with phosphate efficiently changed the product distributions in DTO reaction. Almost $70 \mathrm{C}$-atom \% selectivity to propylene and butylenes with ca. $50 \mathrm{C}$-atom \% selectivity to propylene was achieved for the reaction over P/MCM-68(60). Moreover, the phosphate modification improved the resistance to coke deposition and decreased the selectivity toward aromatics and ethylene. This is probably due to the selective decrease in the number of acid sites on external surface of MCM-68 as confirmed by TIPB and cumene cracking reactions. Furthermore, the phosphate modification decreased the number of strong Lewis acid sites by covering them, providing the resultant catalyst P/MCM-68(60) with high resistance to coke deposition during DTO reaction. The high P/E ratio over P/MCM-68(60) is probably due to the removal of strong Brønsted acid sites with phosphate modification.

\section{References}

[1] J. Verstraete, V. Coupard, C. Thomazeau, P. Etienne, Catal. Today 106 (2005) 62.

[2] E. H. Edwin, J. G. Balchen, Chem. Eng. Sci. 56 (2001) 989.

[3] A. Farshi, F. Shaiyegh, S. H. Burogerdi, A. Dehgan, Pet. Sci. Technol. 29 (2011) 875

[4] A. Corma , F.V. Melo, L. Sauvanaud, F.J. Ortega, Appl. Catal. A 265 (2004) 195.

[5] A. Sardesai, S. Lee, Energy Sources, 27 (2005) 489.

[6] S.A. Tabak, S. Yurchak, Catal. Today 6 (1990) 307.

[7] C.D. Chang, A.J. Silvestri, J. Catal. 47 (1977) 249.

[8] C.D. Chang, Stud. Surf. Sci. Catal. 36 (1988) 127.

[9] G. Zhao, J. Teng, Z. Xie, W. Jin, W. Yang, Q. Chen, Y. Tang, J. Catal. 248 (2007) 29. 
[10] J.C. Mol, J. Mol. Catal. A: Chem. 213 (2004) 39.

[11] M.A. Chaar, D. Patel, H.H. Kung, J. Catal. 109 (1988) 463.

[12] G.A. Olah, Catal. Lett. 93 (2004) 1.

[13] K. Asami, Q. Zhang, X. Li, S. Asaoka, K. Fujimoto, Catal. Today 106 (2005) 247.

[14] M. Bjørgen, F. Joensen, K. Lillerud, U. Olsbye, S. Svelle, Catal. Today 142 (2009) 90.

[15] M. Stöcker, Micropor. Mesopor. Mater. 29 (1999) 3.

[16] L. Wu, E.J.M. Hensen, Catal. Today 235 (2014) 160.

[17] U. Olsbye, S. Svelle, M. Bjørgen, P. Beato, T.V.W. Janssens, F. Joensen, S. Bordiga, K.P. Lillerud, Angew. Chem. Int. Ed. 51 (2012) 5810.

[18] H. Yamazaki, H. Shima, H. Imai, T. Yokoi, T. Tatsumi, J. N. Kondo, Angew. Chem. Int. Ed. 50 (2011) 1853.

[19] T. Zhao. T. Takemoto, N. Tsubaki, Catal. Commun. 7 (2006) 647.

[20] A. Iida, R. Nakamura, K. Komura, Y. Sugi, Chem. Lett. 37 (2008) 494.

[21] H. Ito, K. Ooyama, S. Yamada, M. Kume, N. Chikamatsu, U.S. Pat. (2007) 0032379.

[22] K. Omata, Y. Yamazaki, Y.Watanabe, K. Kodama, M. Yamada, Ind. Eng. Chem. Res. 48 (2009) 6256.

[23] J.C. Védrine, A. Auroux, P. Dejaifve, V. Ducarme, H. Hoser, S. Zhou, J. Catal. 73 (1982) 147.

[24] A. Rahman, G. Lemay, A. Adnot, S. Kaliaguine, J. Catal. 112 (1988) 453.

[25] M. Kaarsholm, F. Joensen, J. Nerlov, R. Cenni, J. Chaouki, G.S. Patience, Chem. Eng. Sci. 62 (2007) 5527

[26] J. Liu, C. Zhang, Z. Shen, W. Hua, Y. Tang, W. Shen, Y. Yue, H. Xu, Catal. Commun. 10 (2009) 1506.

[27] D.V. Vu, Y. Hirota, N. Nishiyama, Y. Egashira, K. Ueyama, J. Jpn. Petrol. Inst. 53 (2010) 232.

[28] H.-G. Jang, H.-K. Min, S.B. Hong, G. Seo, J. Catal. 299 (2013) 240.

[29] M. Dyballa, E. Klemm, J. Weitkamp, M. Hunger, Chem. Ing. Tech. 85 (2013) 1719.

[30] J.C. Vedrine, A. Auroux, P. Dejaifve, V. Ducarme, H. Hoser, S. Zhou, J. Catal. 73 (1982) 147. 
[31] F. Yaripour, Z. Shariatinia, S. Sahebdelfar, A. Irandoukht, Micropor. Mesopor. Mater. 203 (2015) 41 .

[32] A. Iida, R. Nakamura, K. Komura, Y. Sugi, Chem. Lett. 37 (2008) 494.

[33] T.-S. Zhao, T. Takemoto, Y. Yoneyama, N. Tsubaki, Chem. Lett. 34 (2005) 970.

[34] T. Inui, H. Matsuda, O. Yamase, H. Nagata, K. Fukuda, T. Ukawa, A. Miyamoto, J. Catal. 98 (1986) 491.

[35] D.L. Dorset, S.C. Weston, S.S. Dhingra, J. Phys. Chem. B 110 (2006) 2045.

[36] Ch. Baerlocher, L.B. McCusker, D.H. Olson, Atlas of Zeolite Framework Types, sixth ed., Elsevier, Amsterdam, 2007. <http://www.iza-structure.org/databases/>.

[37] Y. Kubota, S. Inagaki, Top. Catal. 58 (2015) 480.

[38] Y. Kubota, S. Inagaki, K. Takechi, Catal. Today 226 (2014) 109.

[39] T. Shibata, S. Suzuki, H. Kawagoe, K. Komura, Y. Kubota, Y. Sugi, J.-H. Kim, G. Seo, Micropor. Mesopor. Mater. 116 (2008) 216.

[40] T. Shibata, H. Kawagoe, H. Naiki, K. Komura, Y. Kubota, Y. Sugi, J. Mol. Catal. A: Chem. 297 (2009) 80.

[41] S. Ernst, S.P. Elangovan, M. Gerstner, M. Hartmann, S. Sauerbeck, Abstr 14th Int Zeol. Conf. 2004, 982.

[42] S. Inagaki, K. Takeshi, Y. Kubota, Chem. Commun. 46 (2010) 2662.

[43] S.P. Elangovan, M. Ogura, S. Ernst, M. Hartmann, S. Tontisirin, M.E. Davis, T. Okubo, Micropor. Mesopor. Mater. 26 (2006) 210.

[44] M. Sasaki, Y. Sato, Y. Tsuboi, S. Inagaki, Y. Kubota, ACS Catal. 4 (2014) 2653.

[45] S. Park, Y. Watanabe, Y. Nishita, T. Fukuoka, S. Inagaki, Y. Kubota, J. Catal. 319 (2014) 265.

[46] M. Niwa, K. Katada, Catal. Surv. Jpn. 1 (1997) 215.

[47] H. Yamazaki, H. Shima, H. Imai, T. Yokoi, T. Tatsumi, J. N. Kondo, J. Phys. Chem. C 116 (2012) 24091.

[48] B. Gil, G. Košová, J. Cejka, Micropor. Mesopor. Mater. 129 (2010) 256.

[49] W. G. Appleby, J. W. Gorbson, G. W. Good, Ind. Eng. Chem. Process Des. Devel. 1 (1962) 102. 
[50] G. A. Olah, J. Org. Chem. 66 (2001) 5943.

[51] F. Bleken, M. Bjørgen, L. Palumbo, S. Bordiga, S. Svelle, K.-P. Lillerud, U. Olsbye, Top Catal. 52 (2009) 218.

[52] P. Vogel, Stud. Org. Chem. (4th. Ed.) (1985) 167. 
Table 1 Physicochemical properties of catalysts used in this work.

\begin{tabular}{|c|c|c|c|c|}
\hline $\begin{array}{l}\text { Catalyst } \\
\left(^{(\mathrm{Si} / \mathrm{Al})^{a}}\right.\end{array}$ & $\mathrm{P} / \mathrm{Al}^{a}$ & $\begin{array}{l}\text { Specific surface area } \\
\qquad / \mathrm{m}^{2} \mathrm{~g}^{-1}\end{array}$ & $\begin{array}{l}\text { Micropore volume } \\
\qquad / \mathrm{cm}^{3} \mathrm{~g}^{-1}\end{array}$ & $\begin{array}{l}\text { Number of acid sites } \\
\qquad / \mathrm{mmol} \mathrm{g}^{d}\end{array}$ \\
\hline MCM-68(60) & 0.0 & 498 & 0.182 & 0.208 \\
\hline P/MCM-68(60) & 1.9 & 416 & 0.147 & 0.187 \\
\hline MCM-68(84) & 0.0 & 501 & 0.186 & 0.142 \\
\hline
\end{tabular}

$a$ Bulk Si/Al and P/Al molar ratios were determined by ICP-AES analysis.

$b$ Specific surface areas of the catalysts were calculated using the Brunauer-Emmett-Teller (BET) equation on the $\mathrm{N}_{2}$ adsorption isotherms.

$c$ Micropore volumes of the catalysts were calculated by the $t$-plot method based on the adsorption isotherms.

$d$ The number of acid sites was estimated by $\mathrm{NH}_{3}$-TPD using TCD detector. 
Table 2

DTO reactions over MCM-68 and phosphate-loaded MCM-68 (time on stream $=5$ min). ${ }^{a}$

\begin{tabular}{|c|c|c|c|c|c|c|c|c|c|c|c|c|c|}
\hline \multirow{2}{*}{$\begin{array}{c}\text { Catalyst }^{b} \\
{[\mathrm{Si} / \mathrm{Al}]}\end{array}$} & \multirow{2}{*}{$\begin{array}{c}\text { Conv. }^{c} \\
{[\%]}\end{array}$} & \multicolumn{9}{|c|}{ Product distribution $^{d}[\mathrm{C}-\%]$} & \multirow{2}{*}{$\begin{array}{l}\text { M.B. } \\
\text { /C-\% }\end{array}$} & \multirow{2}{*}{$\mathrm{P} / \mathrm{E}^{f}$} & \multirow{2}{*}{$\begin{array}{c}\text { Content } \\
\text { of coke } \\
{[\mathrm{mg}-\text { coke }} \\
\left.(\mathrm{g}-\mathrm{cat})^{-1}\right]\end{array}$} \\
\hline & & $\mathrm{MeOH}$ & $\mathrm{C} 1+\mathrm{C} 2+\mathrm{C} 3$ & $\mathrm{C} 2=$ & $\mathrm{C} 3=$ & $\mathrm{C} 4$ & $\mathrm{C} 4=$ & $\mathrm{C} 5+\mathrm{C} 5=$ & $\geq \mathrm{C} 6$ & aromatics & & & \\
\hline MCM-68(60) & 96.2 & 4.0 & 1.3 & 2.2 & 37.2 & 5.9 & 21.4 & 11.4 & 12.2 & 4.3 & 83.7 & 16 & 56 \\
\hline P/MCM-68(60) & 96.7 & 6.7 & 0.3 & 1.0 & 43.4 & 1.1 & 25.4 & 10.5 & 9.5 & 2.1 & 95.7 & 42 & 23 \\
\hline MCM-68(84) & 93.1 & 4.7 & 0.8 & 2.6 & 40.8 & 3.4 & 20.9 & 12.7 & 10.0 & 4.2 & 85.8 & 16 & 39 \\
\hline
\end{tabular}

$a$ Reaction conditions: catalyst weight, $50 \mathrm{mg} ; \mathrm{W} / \mathrm{F}=10.0 \mathrm{~g}$-cat h mol ${ }^{-1}$; pellet size, 500-600 $\mu \mathrm{m}$; He gas flow rate, 40 $\mathrm{cm}^{3}$ (N.T.P.) $\mathrm{min}^{-1}$; partial pressure of DME $=4.9 \mathrm{kPa}$; reaction temperature, $400{ }^{\circ} \mathrm{C}$. Pretreatment conditions: $550{ }^{\circ} \mathrm{C}, 1$ h, air flow rate, $40 \mathrm{~cm}^{3}$ (N.T.P.) $\mathrm{min}^{-1}$.

$b$ Values in parentheses are $\mathrm{Si} / \mathrm{Al}$ ratios determined by ICP-AES analysis.

$c$ DME conversion $=\left\{1-\left(\mathrm{C}\right.\right.$-atoms of $\left.\mathrm{DME}_{\text {output }}\right) /\left(\mathrm{C}\right.$-atoms of $\left.\left.\mathrm{DME}_{\text {input }}\right)\right\} \times 100$.

$d$ Product yield $=\{(\mathrm{C}$-atoms of the product $) /(\mathrm{C}$-atoms of DMEinput $-\mathrm{C}$-atoms of DMEoutput $)\} \times\{(\mathrm{DME}$ conv.(C-\%) $\}$. $e$ Material balance $=\left(\right.$ Total $\mathrm{C}$-atoms of products and $\left.\mathrm{DME}_{\text {output }}\right) /\left(\mathrm{C}\right.$-atoms of $\left.\mathrm{DME}_{\text {input }}\right) \times 100$.

$f$ Propylene/ethylene molar ratio in the products.

$g$ Catalysts used in DTO reaction for 305 min were used in thermogravimetric analysis. The weight loss observed from 300 to $700{ }^{\circ} \mathrm{C}$ in a thermogravimetirc analysis was regarded as coke contents. 


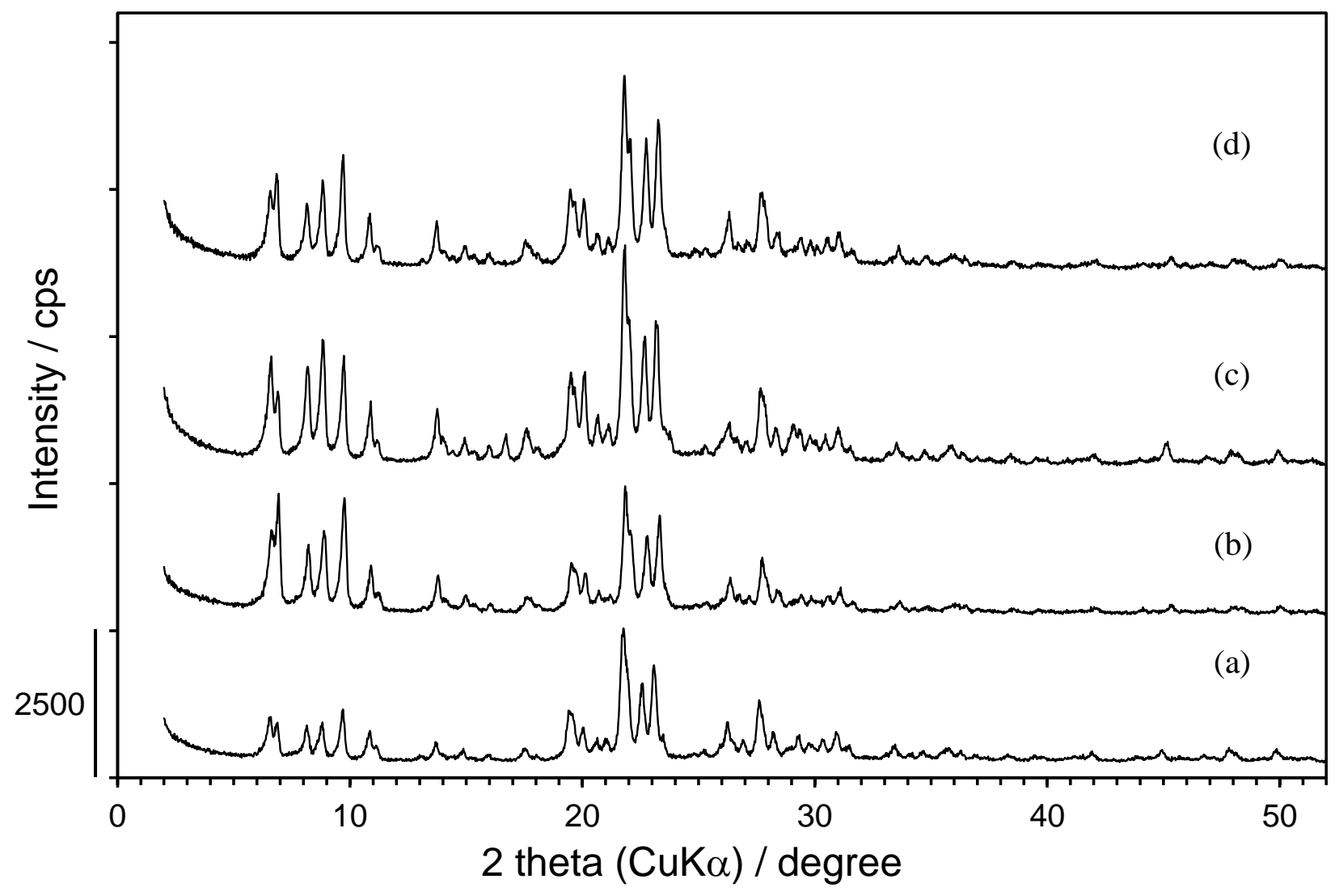

Fig. 1. XRD patterns of (a) MCM-68(10), (b) MCM-68(60), (c) P/MCM-68(60) and (d) MCM-68(84). The phosphate-loaded samples are designated as P/MCM-68. The number in parentheses is $\mathrm{Si} / \mathrm{Al}$ molar ratio. 
(a)

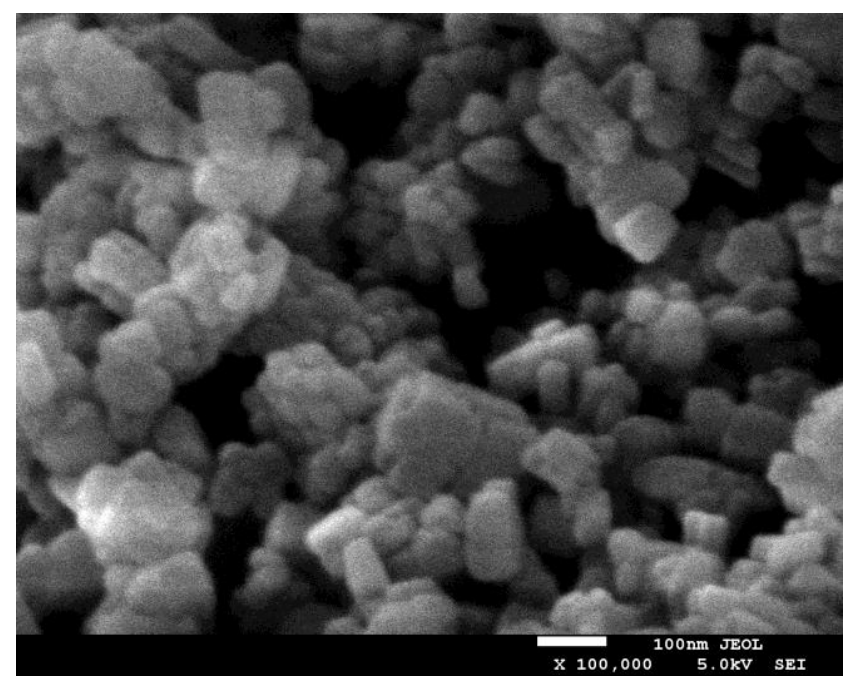

(c)

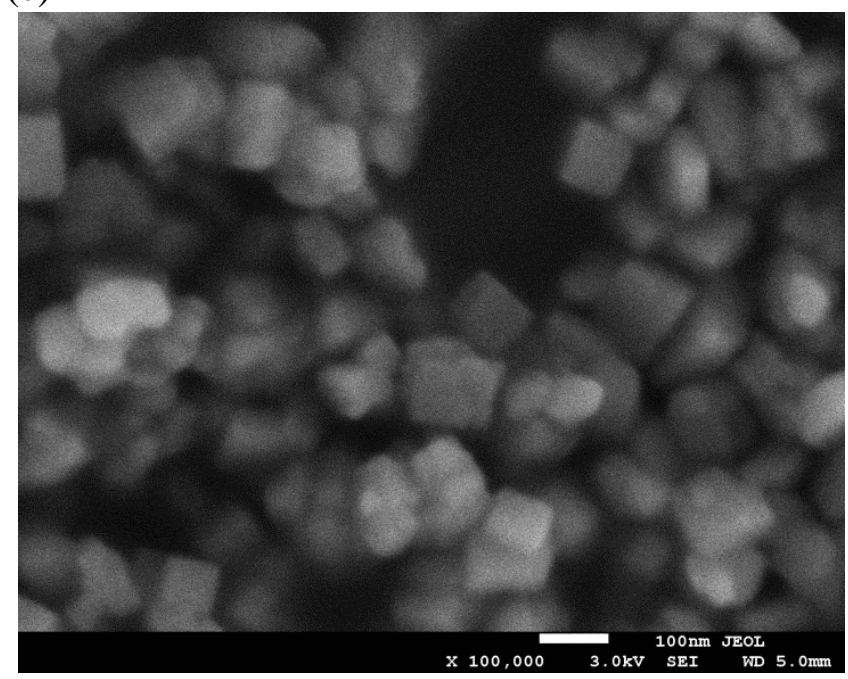

(b)

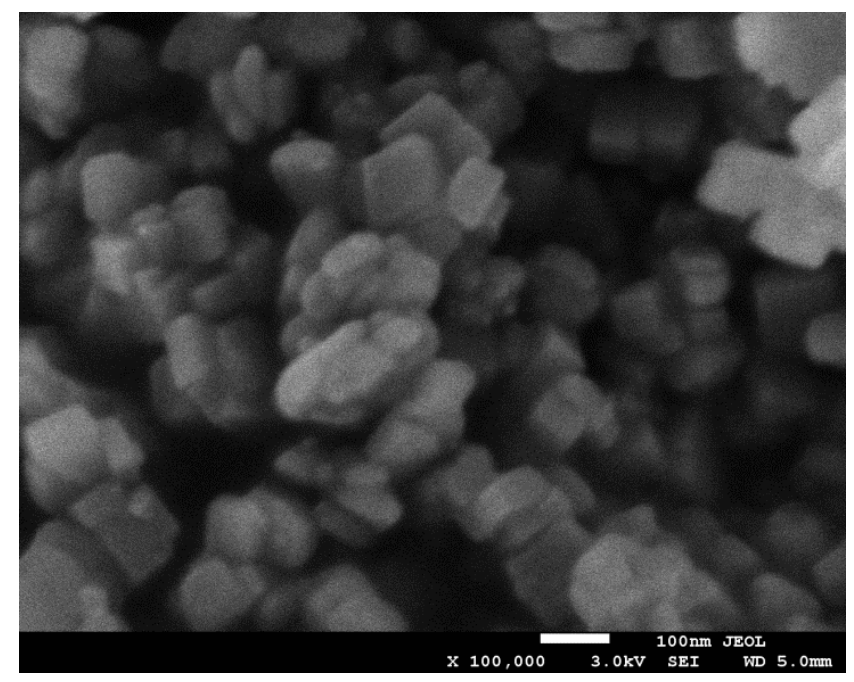

$100 \mathrm{~nm}$

Fig. 2. Typical SEM images of (a) MCM-68(10), (b) MCM-68(60) and (c) P/MCM-68(60). 


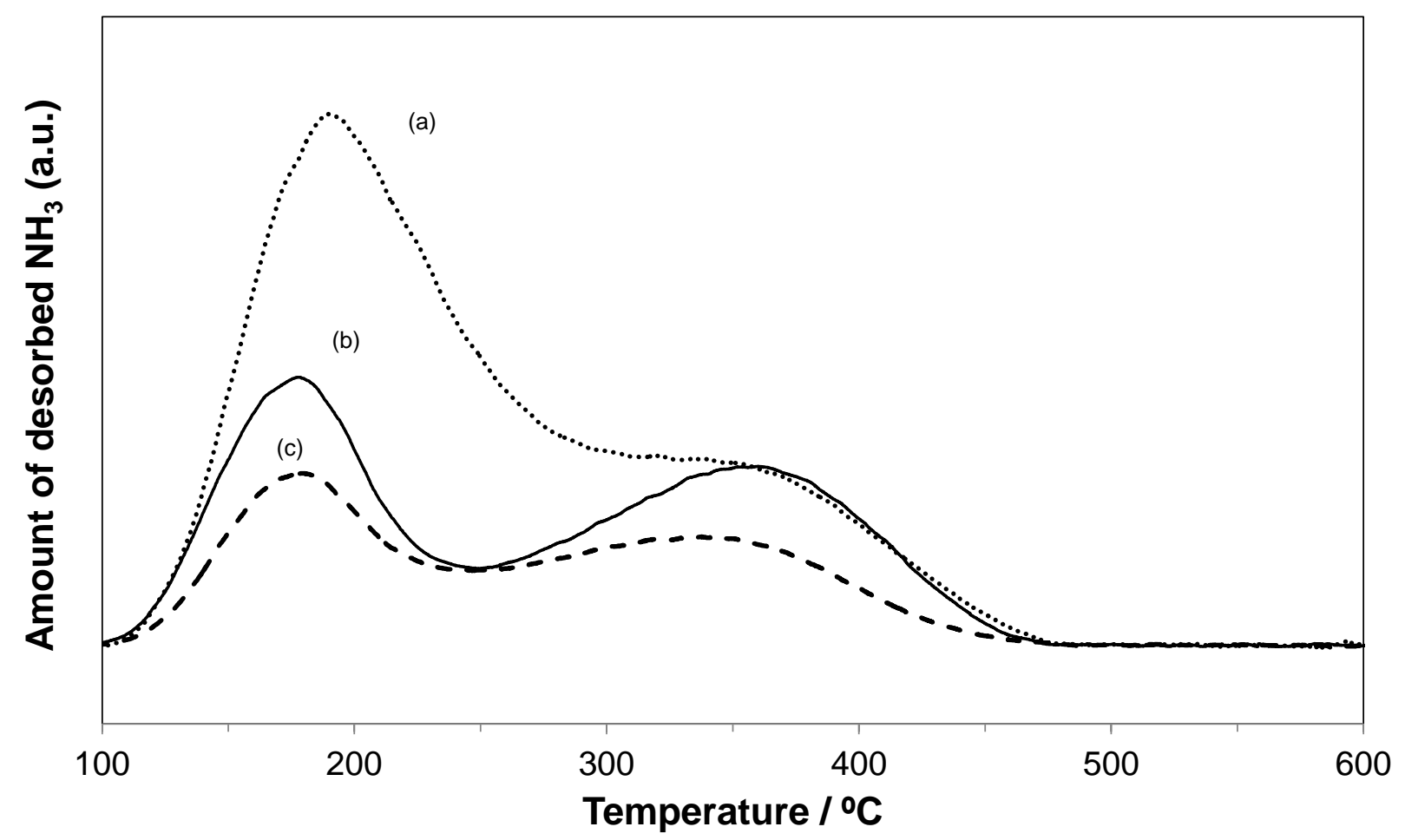

Fig. 3. $\mathrm{NH}_{3}$-TPD profiles of (a) P/MCM-68(60), (b) MCM-68(60) and (c) MCM-68(84). 
(a)

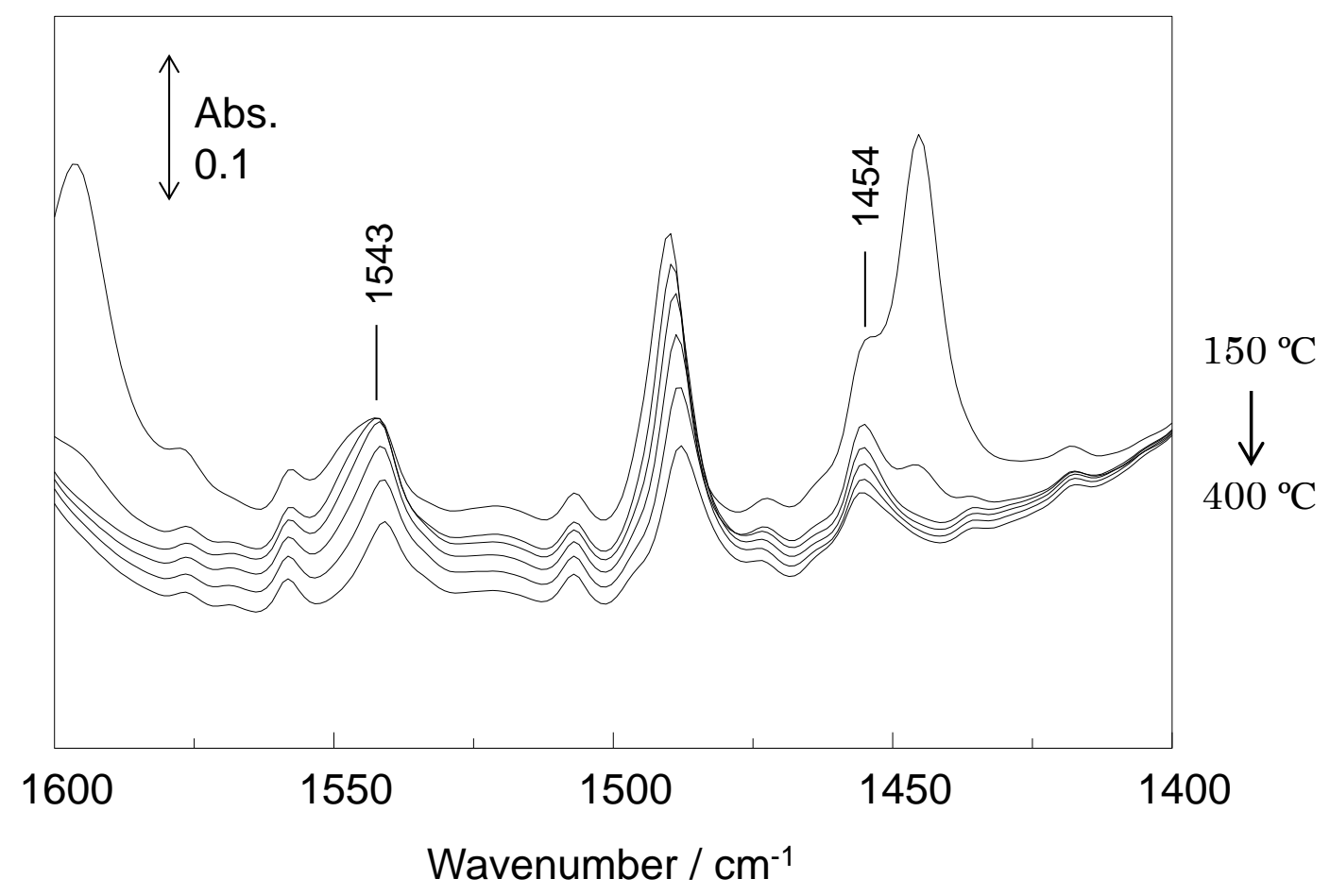

(b)

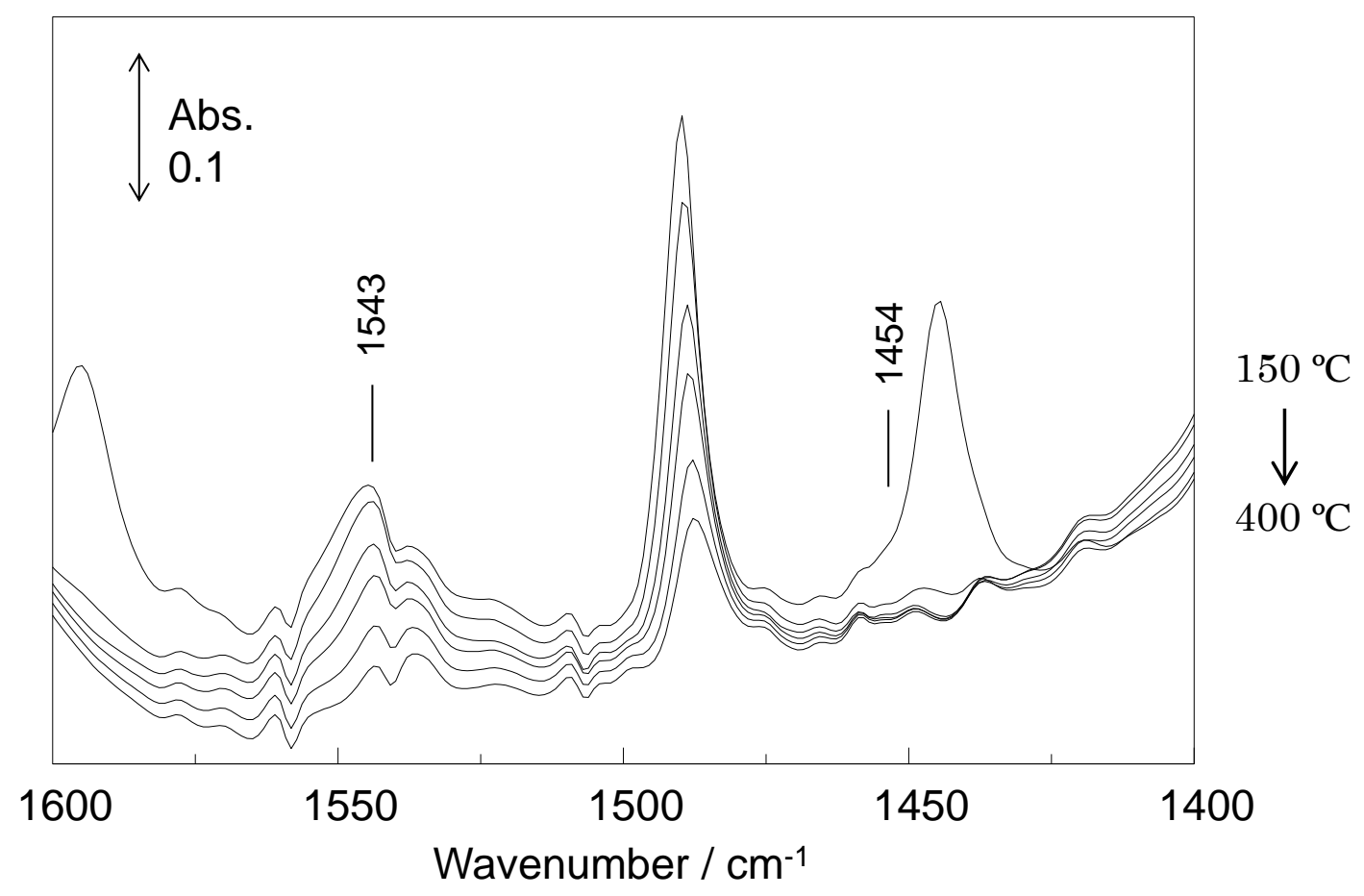

Fig. 4. IR spectra of pyridine adsorbed on (a) MCM-68(60) and (b) P/MCM-68(60). The upper curves are related to a low temperature and the bottom curves are related to a high temperature during IR measurements. Pretreatment conditions: temperature, $550{ }^{\circ} \mathrm{C}$; period, $1 \mathrm{~h}$ under vacuum. 


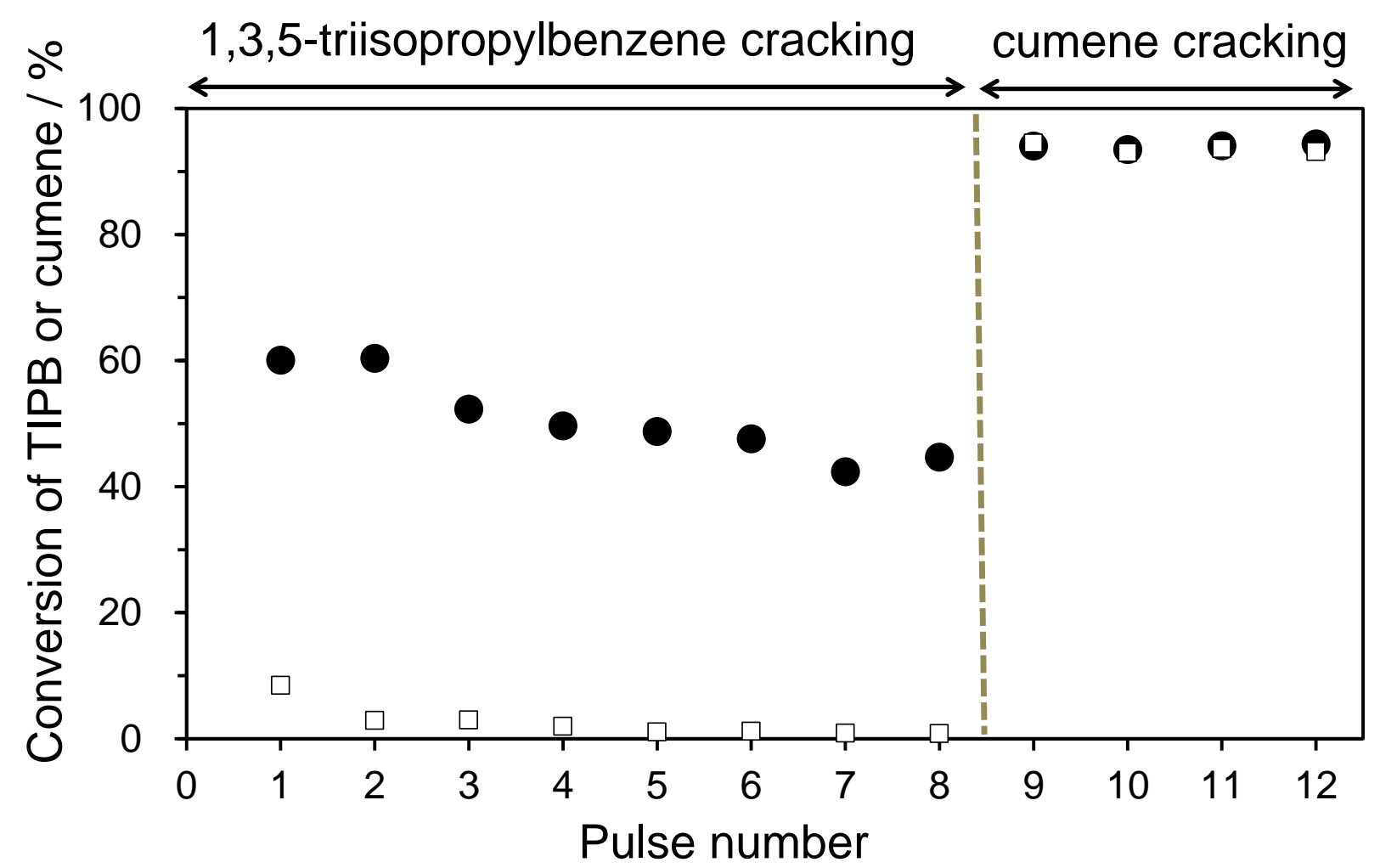

Fig. 5. Catalytic activity in the cracking of 1,3,5-triisopropylbenzene (TIPB) or cumene over $(\bullet)$ MCM-68(60) and (口) P/MCM-68(60) at $300^{\circ} \mathrm{C}$. Reaction conditions: catalyst, $20 \mathrm{mg}$; temperature, $300{ }^{\circ} \mathrm{C}$; Pretreatment conditions: temperature, $550{ }^{\circ} \mathrm{C}$; period, $1 \mathrm{~h}$; air flow rate, $40 \mathrm{~cm}^{3}$ (N.T.P.) $\mathrm{min}^{-1}$. 
(a)

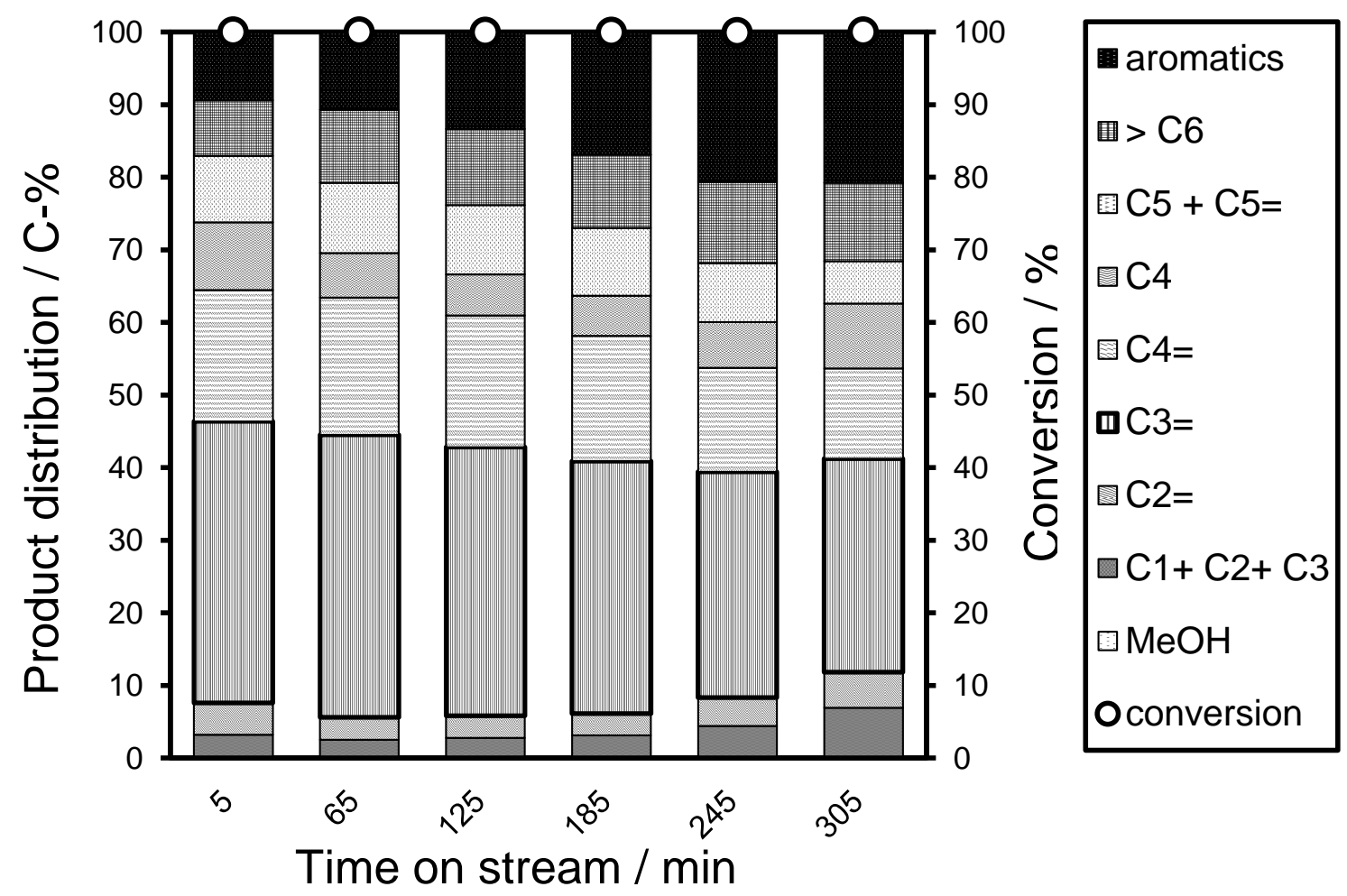

(b)

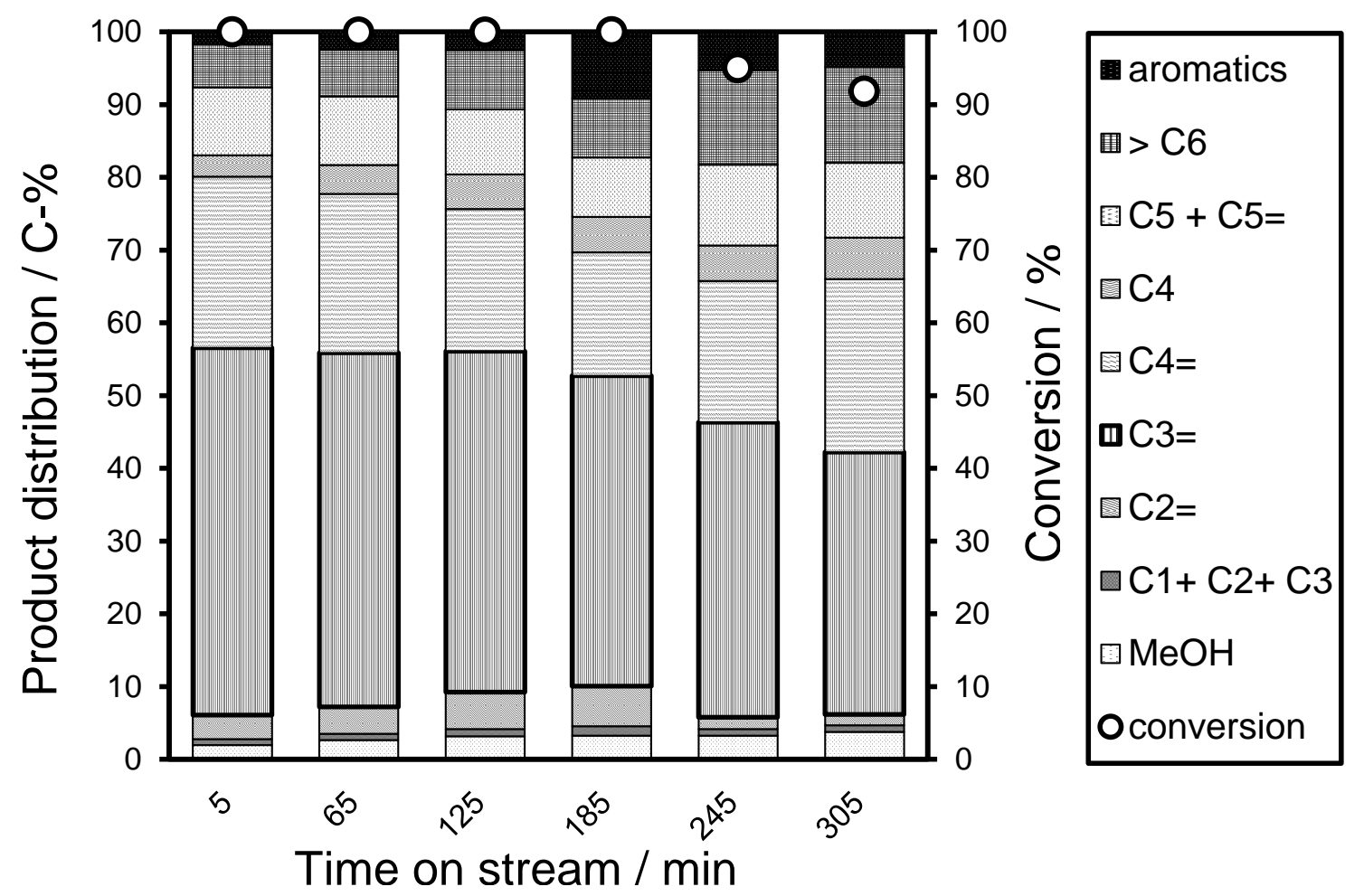


(c)

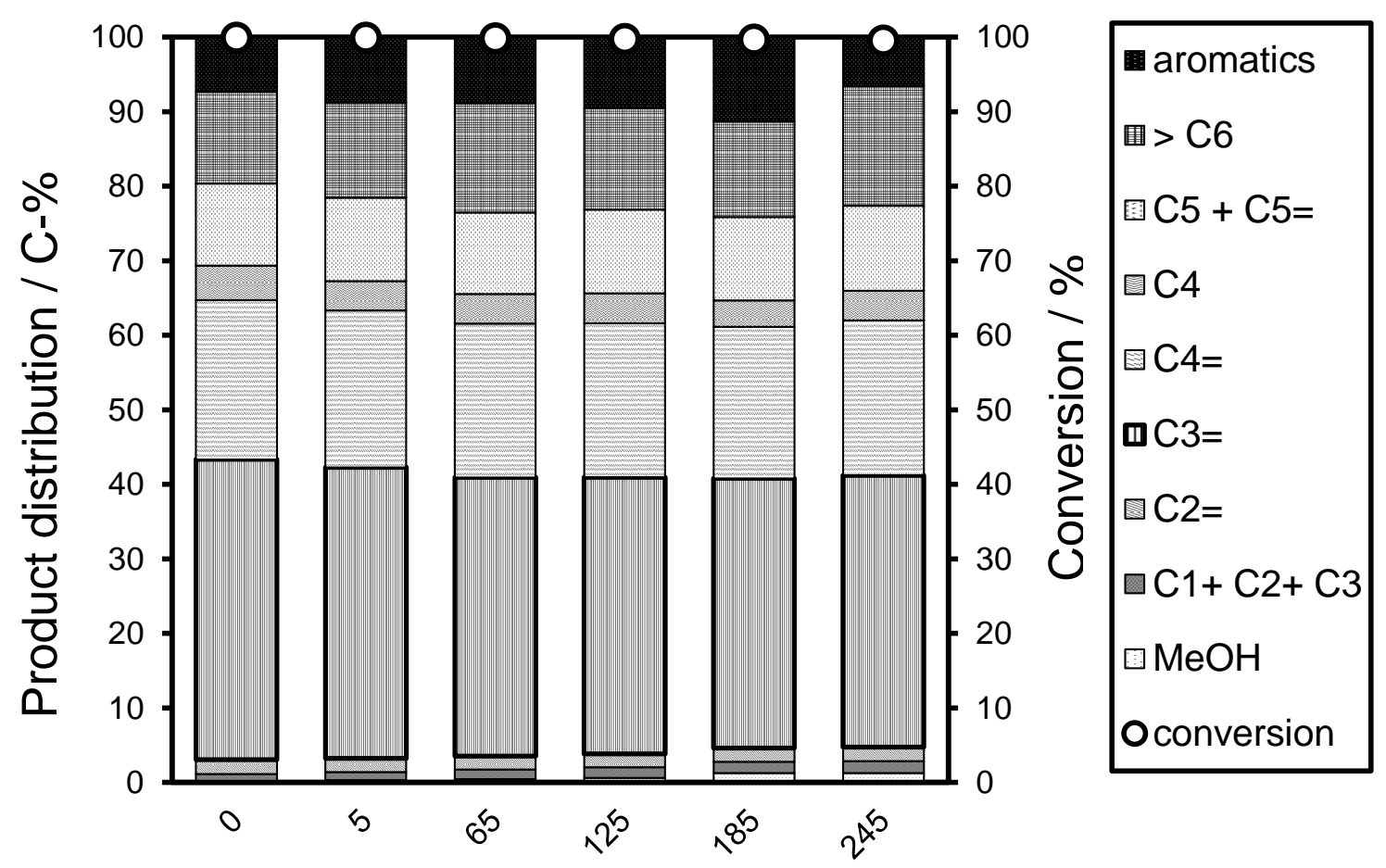

Time on stream / min

(d)

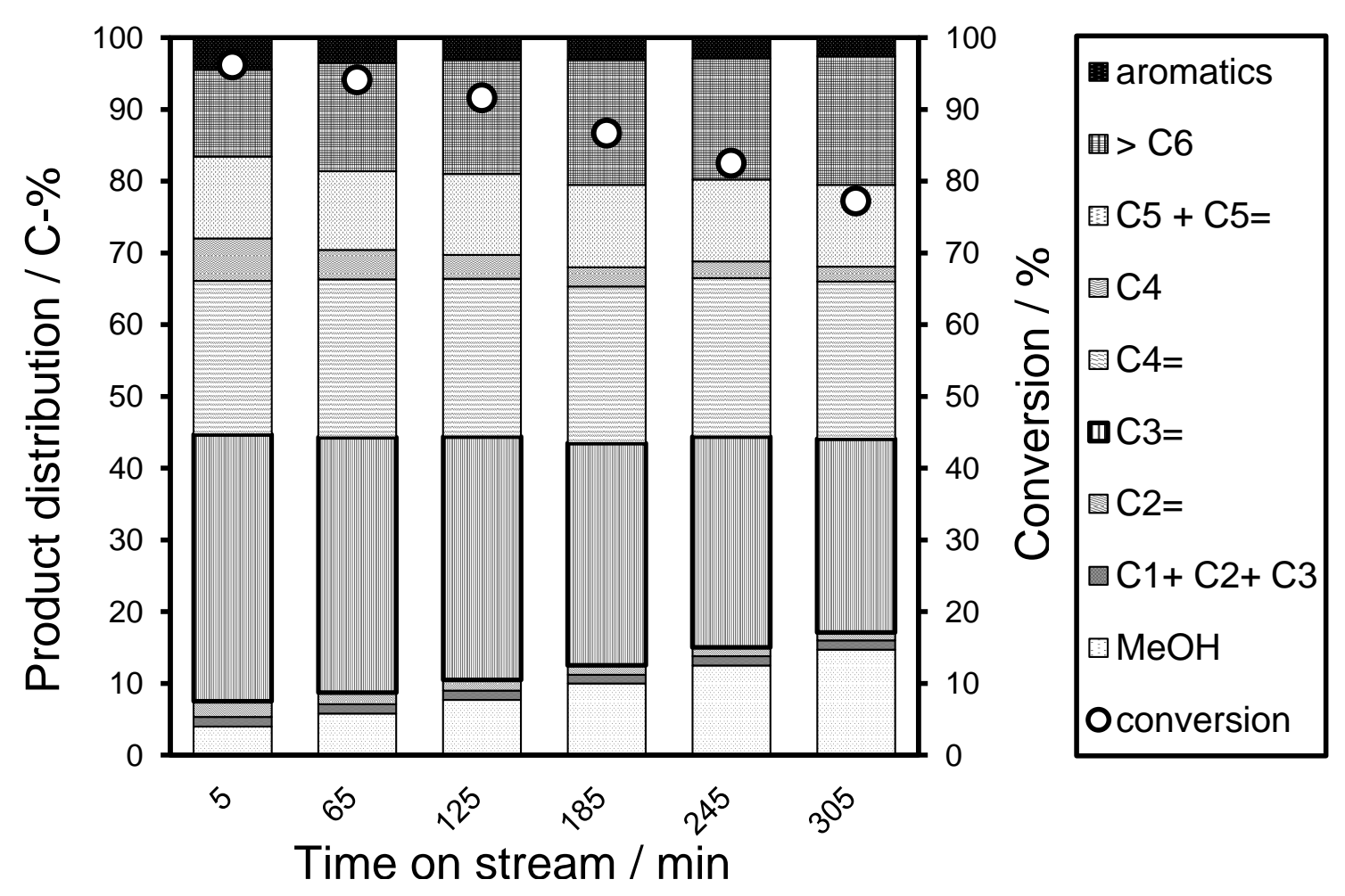


(e)

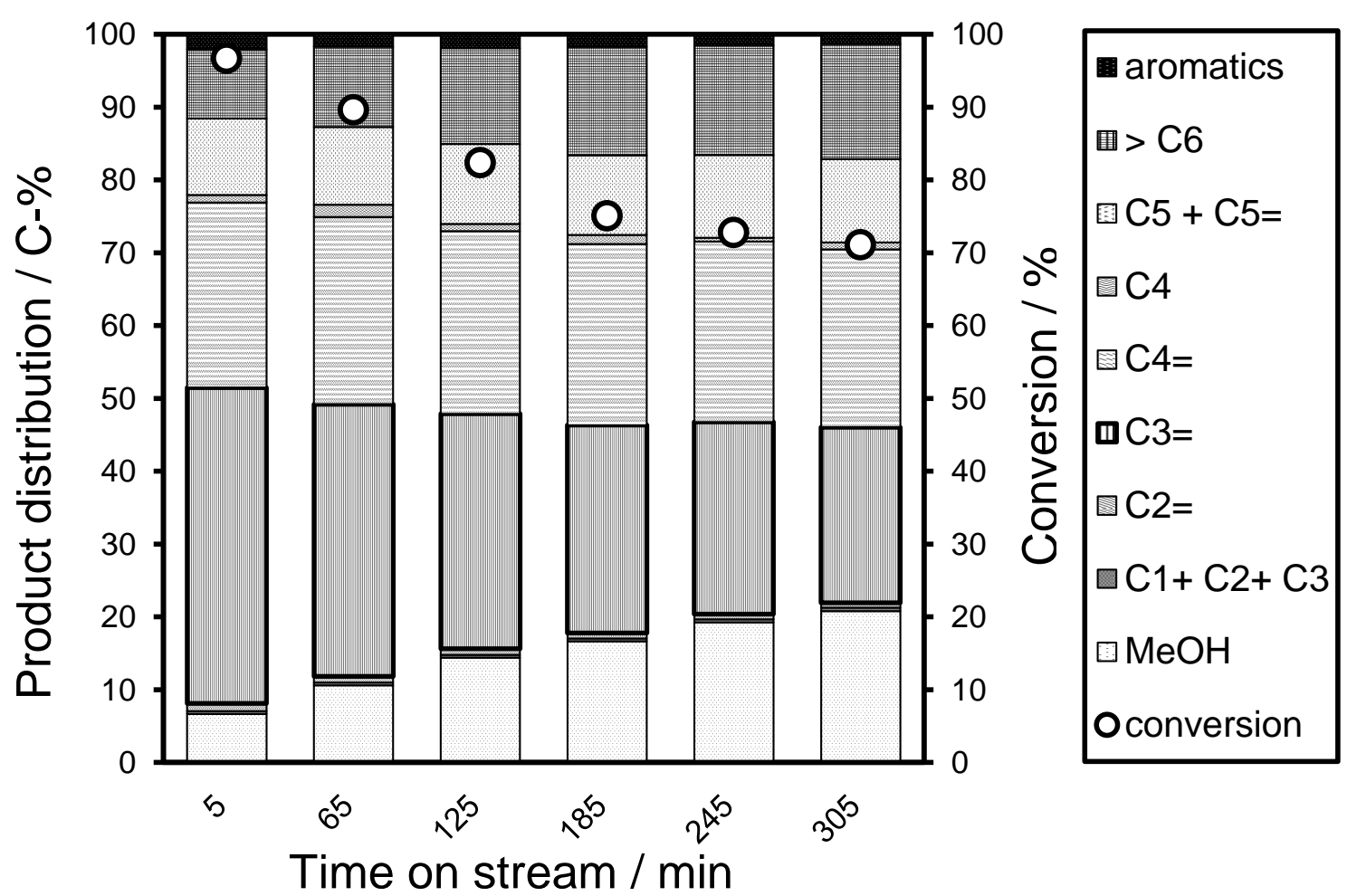

(f)

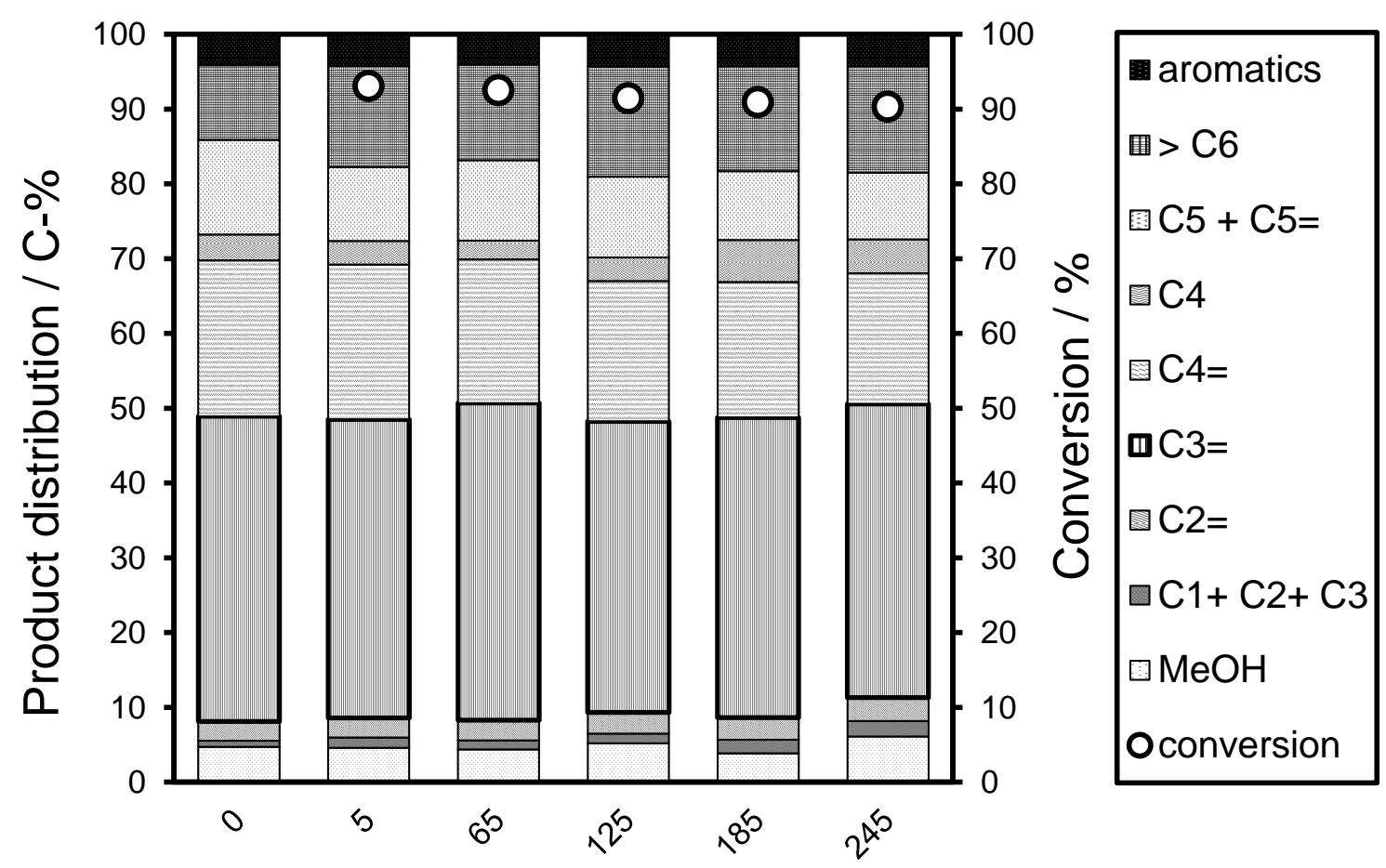

Time on stream / min

Fig. 6. Dimethyl ether conversion and product distributions in the DTO reactions over (a, d) MCM-68(60), (b, e) P/MCM-68(60) and (c, f) MCM-68(84). Reaction conditions: catalyst, (a-c) 100 $\mathrm{mg}$ and (d-f) $50 \mathrm{mg}$; temperature, $400{ }^{\circ} \mathrm{C}$; He flow rate, $40 \mathrm{~cm}^{3}$ (N.T.P.) $\mathrm{min}^{-1}$. Pretreatment conditions: temperature, $550{ }^{\circ} \mathrm{C}$; period, $1 \mathrm{~h}$; air flow rate, $40 \mathrm{~cm}^{3}$ (N.T.P.) $\mathrm{min}^{-1}$. 
Graphical Abstract

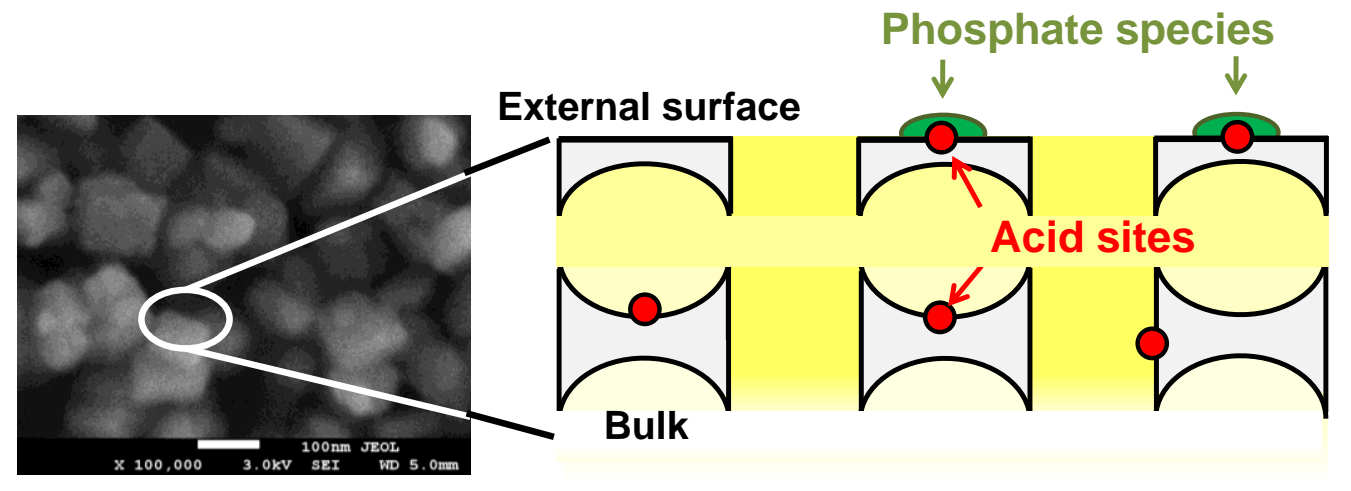

